\title{
Legume consumption in Sweden: a descriptive cross-sectional study
}

\author{
$\underline{\text { Steib Céline }}^{1}$, Ingegerd Johansson ${ }^{2}$, Mohammed Hefni ${ }^{3}$ and Cornelia Witthöft ${ }^{3}$ \\ ${ }^{1}$ Linnaeus University, Department of Chemistry and Biomedical Sciences, Kalmar, Sweden, \\ ${ }^{2}$ Umeå University, Faculty of Medicine, Department of Public Health and Clinical Medicine, Nutritional Research, \\ Umeå, Sweden and \\ ${ }^{3}$ Department of Chemistry and Biomedical Sciences, Linnaeus University, Kalmar, Sweden
}

\section{Abstract}

Despite the growing evidence supporting legume consumption as part of healthy and sustainable diet, little information is known on legume intake in the Swedish population. The aim of the present study was to describe legume consumers in Sweden, their nutrient intake and study the association with biomarkers of nutritional status using food consumption and biomonitoring data from Swedish adults in the 2010-11 National Riksmaten survey. Total legume intake - including pulses, fresh legumes, soy products, peanuts, sprouts and mixed meals with legumes - was estimated using a web-based 4-d food records in adults 18-80 years $(\mathrm{n}=1772)$. A range of biomarkers including non-fasted plasma ferritin and folate, as well as erythrocyte folate, were measured for a subsample of the population $(n=282)$. Legumes were consumed by $44 \%$ of the population, median intake was $36 \mathrm{~g} / \mathrm{d}(\mathrm{Q} 1=16$; Q3 $=71 ; \mathrm{n}=$ 777). Legumes provided on average $3.3 \%$ of individual's total energy intake (\%E) with no significant difference between sexes. Pulses were consumed by $33 \%$ of consumers contributing to $3.2 \pm 2.8 \% \mathrm{E}$ intake whereas soy products were consumed by $8.6 \%$ of legume consumers but contributing to $6 \pm 7.5 \% \mathrm{E}$. Legume intake among self-reported vegetarians $(\mathrm{n}=55)$ was significantly higher $(\mathrm{p}<0.000)$ than for non-vegetarians, with mean daily intakes of $92 \pm 99 \mathrm{~g} / \mathrm{d}$ and $21 \pm 42 \mathrm{~g} / \mathrm{d}$, respectively. Age (p 0.0066) was significantly higher in Q4 of legume intake and alcohol consumption was significantly lower ( $\mathrm{p}$ 0.0008); BMI, gender, smoking habits, education and total energy intake did not differ. $23 \%$ of legume consumers have a fiber intake of $25-35 \mathrm{~g} / \mathrm{d}$ whereas only $11 \%$ of non-consumers reach recommended intake ( $p$ 0.0001). Iron, folate and dietary fiber intakes were significantly higher $(p<0.000)$ in $Q 4$ of legume intake. $32 \%$ of legume consumers meet recommended intakes of folate (RI $300 \mu \mathrm{g} / \mathrm{d}$ ) versus $18 \%$ for non-consumers ( $\mathrm{p} 0.000$ ). Notably, $5.76 \%$ of women of repro-

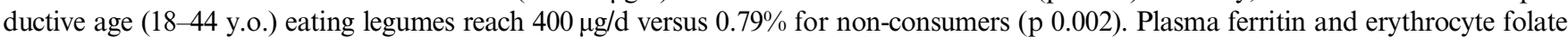
levels did not differ between legume consumers and non-consumers. However, for women in reproductive age $(n=31)$, plasma folate levels

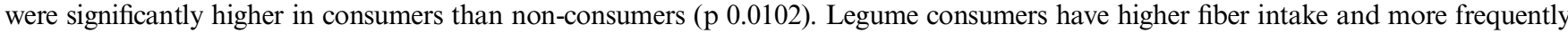
meet recommended folate intakes while maintaining adequate iron intake. In conclusion, legume consumers in Sweden are characterized by a defined diet pattern that generally is associated with better health.

\section{Conflict of Interest}

There is no conflict of interest. 